\title{
Laparoscopic Intervention after Ventriculoperitoneal Shunt: A Case Report, Systematic Review, and Recommendations
}

\author{
Morva Tahmasbi Rad ${ }^{1}$, Sandra Bogdanyova ${ }^{2}$, Lisa M Wilhelm ${ }^{3}$ Juergen Konczalla ${ }^{4}$, Florian J Raimann ${ }^{5}$, Markus Wallwiener ${ }^{6}$,
} Sven Becker ${ }^{7}$

\begin{abstract}
Background: In patients presenting pelvic pathology and a placed ventriculoperitoneal (VP) shunt, there is uncertainty regarding the decision whether to use laparoscopy. The aim of the article is to examine the available literature as well as sharing our own experiences operating on a patient with a VP shunt using laparoscopy.

Materials and methods: We searched online libraries (PubMed, EMBASE, and Google Scholar) for all publications published between January 1975 and December 2018 on our topic. We performed a systematic review and shared our experience with laparoscopy in a patient with shunt and ovarian cancer.

Results: The age of the patients ranged from 1 to 79 years. The operations were performed by the departments of general surgery, gynecology, and urology. The time from the shunt operation to laparoscopy ranged from 5 days to 28 years. In different articles, four important points were considered and discussed: the risk of a shunt infection or complication, technical difficulties carrying out laparoscopy in patients with a VP shunt, the necessity of routine monitoring of the intracranial pressure (ICP) intraoperatively, and perioperative strategies to avoid complications. Conclusion: It seems that a laparoscopic surgery in adults with a VP shunt appears to be a safe option. Based on the results of our case and the review of literature, we consider it necessary to have a neurosurgical consult performed prior to surgery, to have the procedure be carried out by an experienced surgeon, and to avoid complications by implementing recommended precautions.

Keywords: Complication, Laparoscopy, Shunt failure, Ventriculoperitoneal shunt.

World Journal of Laparoscopic Surgery (2020): 10.5005/jp-journals-10033-1397
\end{abstract}

\section{INTRODUCTION}

The approach to abdominal procedures has transitioned toward less invasive techniques. The reduction in postoperative pain, decreases in wound infection, reduced hospital stay and cosmetic benefits have warranted its widespread use. With its increased use, surgeons are presented with a group of patients whose medical conditions are a challenge when performing laparoscopic surgery. Patients treated with a VP shunt represent such a group. ${ }^{1}$

Shunting is the most common treatment of hydrocephalus. Across all age-groups, the prevalence of hydrocephalus is estimated at 1.0 to $1.5 \%^{2}$ and about 100,000 shunts are implanted each year in the developed countries. ${ }^{2,3}$ Hydrocephalus has different etiologies, including malformations, agenesis, infections, mass lesions (tumors, hematomas, cysts, and abscesses), head trauma, and hemorrhages. A VP shunt is a mechanical device designed to transport the excess cerebrospinal fluid (CSF) from or near the point of obstruction to a reabsorption site and is implanted subcutaneously. ${ }^{4}$ The absorption site is usually the abdomen (peritoneum). The valve and reservoir control the fluid withdrawn from the brain. The distal end is a small narrow piece of tubing which leads the excess CSF into the peritoneum (Figs 1 and 2). The unidirectionally designed valve is necessary to prevent the reflux of CSF and intra-abdominal fluid. It allows the fluid to flow only when the pressure inside the skull has exceeded a certain value (usually referred to as the "opening pressure"). ${ }^{3,4}$

The ICP (pressure inside the skull), is normally 7 to $15 \mathrm{~mm} \mathrm{Hg}$ at rest for a mature adult in the supine position. This varies by about $1 \mathrm{~mm} \mathrm{Hg}$ caused by shifting in the production and absorption of CSF. The CSF pressure is shown to be influenced by abrupt changes
1-3,7 Department of Obstetrics and Gynecology, University of Frankfurt, Frankfurt am Main, Germany

${ }^{4}$ Department of Neurosurgery, University of Frankfurt, Frankfurt am Main, Germany

${ }^{5}$ Department of Anesthesiology, University of Frankfurt, Frankfurt am Main, Germany

${ }^{6}$ Department of Obstetrics and Gynecology, University of Heidelberg, Heidelberg, Germany

Corresponding Author: Morva Tahmasbi Rad, Department of Obstetrics and Gynecology, University of Frankfurt, Frankfurt am Main, Germany, Phone: +49-6301-5115, e-mail: Morva.TahmasbiRad@kgu.de How to cite this article: Rad MT, Bogdanyova S, Wilhelm LM, et al. Laparoscopic Intervention after Ventriculoperitoneal Shunt: A Case Report, Systematic Review, and Recommendations. World J Lap Surg 2020;13(1):35-42.

Source of support: Nil

Conflict of interest: None

in the intrathoracic pressure during coughing or intra-abdominal pressure, for example, Valsalva maneuver or communication with the vascular system (venous and arterial). The ICP at 20 to $25 \mathrm{~mm}$ $\mathrm{Hg}$, which is the upper limit of the norm, may require treatment to reduce the ICP. When the ICP exceeds 40 to $50 \mathrm{~mm} \mathrm{Hg}$, the cerebral perfusion decreases to a level causing loss of consciousness and leading to infarction or brain dead.

A rise in the ICP is a result of a pressure rise in the vena cava when insufflating the abdomen with $\mathrm{CO}_{2}$, and this leads to an obstruction of the cerebral veins. Hypercapnia caused by the absorption of

(c) The Author(s). 2020 Open Access This article is distributed under the terms of the Creative Commons Attribution 4.0 International License (https://creativecommons. org/licenses/by-nc/4.0/), which permits unrestricted use, distribution, and non-commercial reproduction in any medium, provided you give appropriate credit to the original author(s) and the source, provide a link to the Creative Commons license, and indicate if changes were made. The Creative Commons Public Domain Dedication waiver (http://creativecommons.org/publicdomain/zero/1.0/) applies to the data made available in this article, unless otherwise stated. 
$\mathrm{CO} 2$ through the peritoneal cavity and the effect of insufflation on ventilation can also lead to dilatation of the intracranial arteries and increases the cerebral perfusion. ${ }^{5-7}$ In healthy people, the increased cerebral perfusion and ICP are temporary and tend to normalize after 10 minutes.

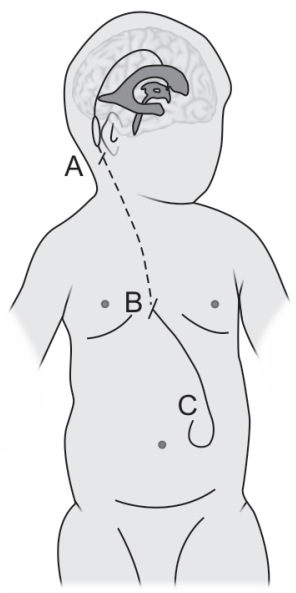

Fig. 1: The shunt has three components: the proximal portion of the shunt which is implanted into the ventricle of the brain, above which the obstruction has occurred; (A) Valve, reservoir, and shunt assistant; ( $A$ and $B$ ) subcutaneously implanted catheter; $(B)$ The shunt enters the abdomen where it can be externalized or clamped; ( $B$ and $C$ ) The distal catheter (intraperitoneal part) which leads to the point where the excess CSF will be drained and be absorbed by the body
In patients with a VP (ventriculoperitoneal) shunt, there have been concerns about performing longer laparoscopic pressure. First, the general fear is based on the thought that increasing the pressure of the abdominal cavity could impair the drainage. Second, the carbon dioxide insufflated into the abdomen could get into the ventricular system and third, the acutely elevated ICP and increased intracranial blood volume are caused by the elevated venous pressure or hypercapnia. ${ }^{8}$ An acute increase in ICP may result in a dangerous combination of hypertension with bradycardia and subsequently a serious neurological complication as a result of a posterior encephalic herniation (Fig. 3). ${ }^{1,5-7,9}$

On the contrary, the presence of a foreign body, such as a VP shunt, and the possibility of a bacterial inoculum being introduced during the operation presumably increase the chance of developing an infection ${ }^{10}$ and adhesions. ${ }^{11-14}$ The direct communication between the peritoneal cavity and the ventricular system in patients with VP shunts could also predispose patients to developing meningitis, shunt malformation, mental changes, seizure disorders, and decreased intellectual abilities. ${ }^{10,13-16}$

Patients who have VP shunts represent a special group who require special attention. ${ }^{17}$ At the time, they have a near to normal life expectancy and are presume to undergo laparoscopic operations as other patients. We are presenting a case of a patient with ascites, a cardiovascular decompensation, and a VP shunt in situ.

Data regarding the intraoperative and postoperative complications or recommendations for patients with VP shunt who undergo laparoscopy are scarce. We present a systematic review of the topic in our article.
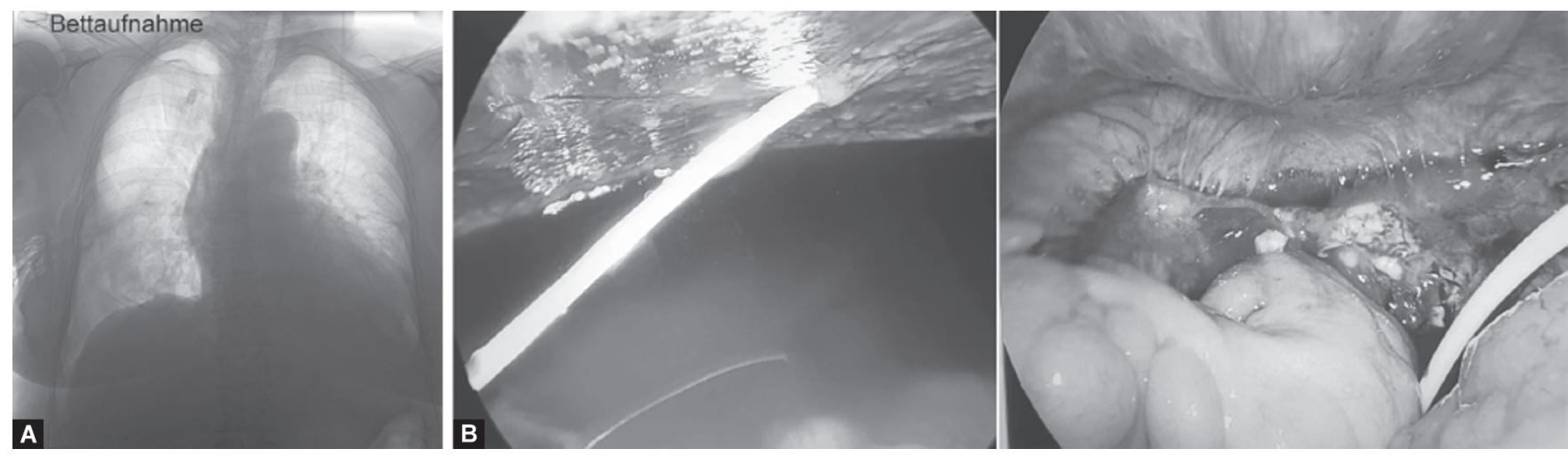

Figs 2A and B: Shunt view in (A) X-ray; (B) Laparoscopy

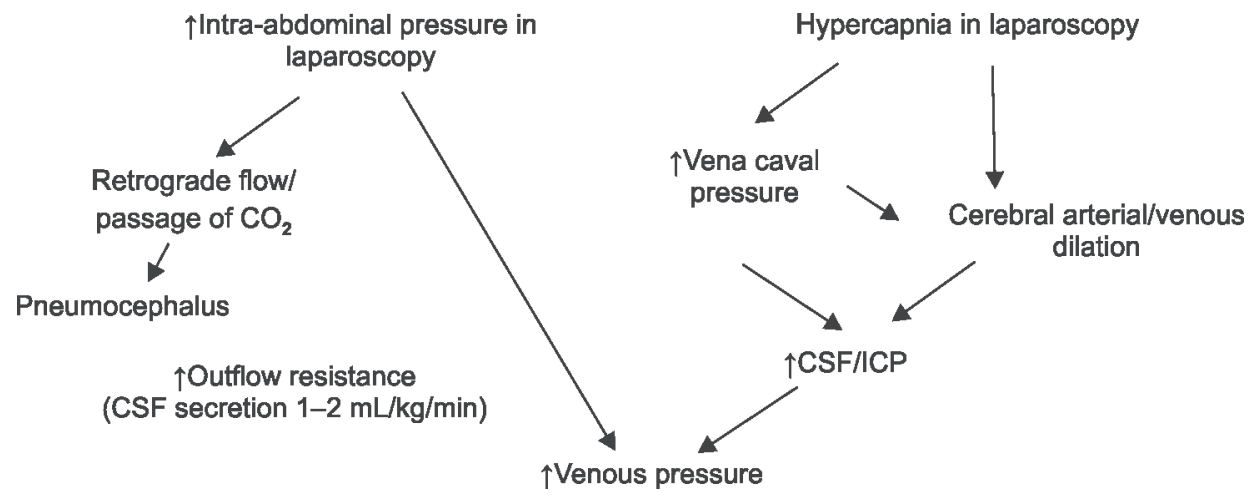

Fig. 3: Ventriculoperitoneal shunt and potential risk of laparoscopy 


\section{Case Description}

A 74-year-old female had been referred to the department of gynecology with ascites. She came to the hospital 3 weeks prior for dyspnea and tachycardia. She was initially admitted to the cardiology department with increased levels of D-dimer, troponin, and pleural effusion. The medical history of the patient revealed a head trauma followed by an epileptic seizure. In 2004, she had undergone several cranial operations resulting in a VP shunt.

As reported by colleagues from the cardiology department, at the time of admission the patient was conscious, alert, and oriented. She presented with tachycardia (heart rate 144/minute), and the electrocardiography (ECG) showed atrial fibrillation and high blood pressure of $155 / 95 \mathrm{~mm} \mathrm{Hg}$. The laboratory results were normal: white cell count, 8.8 trillion cells/L, hemoglobin 15 $\mathrm{g} / \mathrm{dL}$, normal serum electrolytes, and coagulation profile. A blood gas analysis showed the following values: $\mathrm{pH}: 7.47, \mathrm{pO}_{2}: 70 \mathrm{~mm}$ $\mathrm{Hg}, \mathrm{pCO}_{2}: 29 \mathrm{~mm} \mathrm{Hg}, \mathrm{HCO}_{3}: 23 \mathrm{mmol} / \mathrm{L}$, lactate: $15 \mathrm{mg} / \mathrm{dL}$, and $\mathrm{O}_{2}$ saturation $96 \%$. Chest X-rays revealed pleural effusion and lung infiltration. An ultrasound was performed, which showed cholecystolithiasis and ascites. A paracentesis of approximately $6 \mathrm{I}$ of ascites was carried out and a sample of the fluid was sent to the pathology. The atrial fibrillation was treated with beta-blockers, and the patient was started on anticoagulation therapy. The transthoracic echocardiogram had presented a mild mitral and tricuspid insufficiency and an ejection fraction of $40 \%$.

The pathology findings showed non-small cell adenocarcinoma and the patient was referred to the department of internal medicine to rule out lung, pancreas, and gastrointestinal malignancies. There were no tumor or suspicion lesions in the endoscopic ultrasound, esophagogastroduodenoscopy, and colonoscopy. The computed tomography (CT) scan of the thorax and abdomen pointed out only suspicious abdominal retroperitoneal lymph nodes, and there were no other relevant findings. The patient was referred to the department of gynecology to rule out gynecological malignancy.

During the examination in our department, she had normal vital parameters. The abdominal examination showed a distended abdomen. No lesions or tumors were found in vaginal examination. The Pap smear was normal. The vaginal ultrasound revealed small ovaries and an endometrium thickness of $8 \mathrm{~mm}$. To rule out a gynecological malignancy, we proceeded with hysteroscopy, dilatation, curettage, and laparoscopy with biopsies.

In the operating room, the patient was placed in a supine position. After the induction of general anesthesia, an orogastric and a Foley catheter were placed with the patient in the low lithotomy position. A 1-cm umbilical incision was carried out, followed by the placement of the Veress needle and insufflation of the abdomen up to $20 \mathrm{~mm} \mathrm{Hg}$ (high flow technique). After establishing a $20-\mathrm{mm}$ $\mathrm{Hg}$ pneumoperitoneum, a $10-\mathrm{mm}$ port and camera were inserted in the abdominal cavity. The peritoneal contents were visualized, confirming no injury or abnormality. The distal VP shunt tube was lying across a small bowel in the left peritoneum and appeared to be intact without signs of abnormalities. The pneumoperitoneum was reduced and maintained at $14 \mathrm{~mm} \mathrm{Hg}$. Three liters of ascites were excreted. Because of adhesions in the left part of the pelvis, we could not see the left ovary properly. After removing the adhesions, there appeared to be suspicious lesions on the left fallopian tube and the left ovary. We took several biopsies and removed all of them in an EnDo-Bag. The surgical field was examined and there was no bleeding. No drain was inserted. The patient was administered antibiotics (cefuroxime and metronidazole) intraoperatively as well as postoperatively for 5 days.

In the postoperative phase, the patient presented no complications and was discharged 24 hours after the operation. There were no neurological symptoms. A neurosurgical consultation had taken place, and no intervention was recommended. The patient demonstrated an uneventful recovery. The histopathological results showed papillary serous carcinoma of the fallopian tube. The patient underwent an ovarian cancer typical laparotomy. In the 8-month follow-up, the patient showed no neurological complications.

\section{Materials and Methods}

\section{Search Strategy, Study Selection, and Data Extraction}

We searched PubMed, EMBASE, and Google Scholar for all publications between January 1975 and December 2018 with the search terms "ventriculoperitoneal shunt," "laparoscopy," "complications," "management," "cerebral monitoring," and "intracranial pressure".

The preliminary search results and article titles have been reviewed. All studies published with an abstract in English which reported at least one case of laparoscopic operation after VP shunts were potentially eligible for inclusion and have been screened to assess whether a full text was possible to acquire. Then all abstracts and full texts for all potentially eligible studies were reviewed and data were extracted. The relevant abstracts have been selected of this initial pool. A reference list of retrieved relevant articles was screened for other studies. Any disagreement during study selection and the data extraction process was resolved by discussion with the senior author (Sv.B). We excluded studies that were written and published in languages other than English or provided insufficient data.

A total of 136 publications were initially identified as eligible using the mentioned search terms. The inclusion criteria were met in 26 publications which came to $19.11 \%$. A systematic review was performed according to Preferred Reporting Items for Systematic Reviews and Meta-Analysis guidelines (Liberati 2009). ${ }^{18}$ Flowchart 1 summarizes the article's search strategy.

\section{Results}

\section{Population of Reported Patients}

According to our research, 128 cases of laparoscopic operations after VP shunt were reported between 1992 and 2018 (Table 1). The collected data included the gender and the age of the patients, the kind of laparoscopic intervention, time from the shunt insertion to the laparoscopic operation, the pressure of pneumoperitoneum, manipulation with the VP shunt during the operation, and the complications. In our analysis, we specifically focused on different approaches and managements in patients with VP shunts needing laparoscopic intervention. ${ }^{1,2,8,10,17,19-39}$

The age of the patients ranged from 1 to 79 years. The operations were performed by the departments of general surgery, gynecology, and urology. The time from the shunt operation to laparoscopy ranged from 5 days to 28 years. The year the shunt was manufactured ranged from 1975 to 2013.

In different articles, 1,2,8,10,17,19-37,39,40 four important points are considered and discussed: the risk of a shunt infection or complication, technical difficulties carrying out laparoscopy in patients with a VP shunt, the necessity of routine monitoring of 
Flowchart 1: Flowchart of articles during the review process

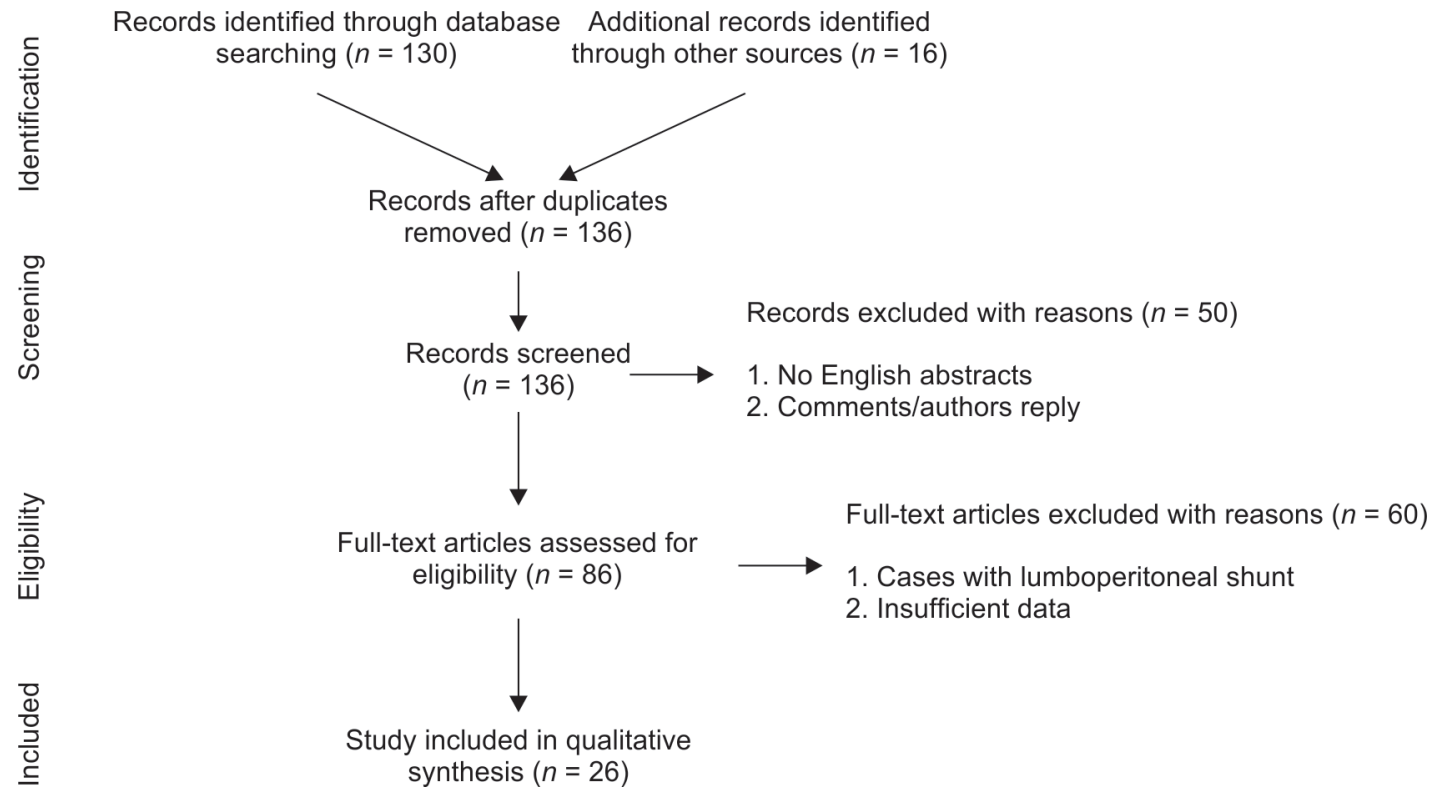

the ICP intraoperatively, and perioperative strategies to avoid complications.

\section{Reported Cases, Complications, and Technical Difficulties}

The pressure used for the pneumoperitoneum was between $8 \mathrm{~mm} \mathrm{Hg}$ and $50 \mathrm{~mm} \mathrm{Hg}$, mostly $12 \mathrm{~mm} \mathrm{Hg}$. 1,2,8,10,17,19-37,39,40 The following complications occurred: one case of massive subcutaneous emphysema, 11 cases of conversion to laparotomy due to extensive inflammation, gangrenous situation, ${ }^{10,20}$ a large tumor, and adhesions. ${ }^{21,36}$ One case of shunt failure directly after the operation, ${ }^{24}$ eight cases of postoperative VP shunt removal or revision due to infection, ${ }^{1,2,8,10}$ one case of multiple organ failure and death, ${ }^{20}$ and one case of pneumocephalus. ${ }^{36}$

Two cases of cancer with the VP shunt were reported, one prostatectomy in prostate cancer, ${ }^{27}$ and one colectomy in cecal cancer. ${ }^{38}$ In all the cases the traditional laparoscopy was used, except for one where robotic hysterectomy was carried out. ${ }^{33}$

The first reported case of laparoscopic surgery having complications with a VP shunt was described by Schwed et al. ${ }^{19}$ They reported a 73-year-old woman who underwent a laparoscopic cholecystectomy 10 days after the insertion of a VP shunt. She suffered subcutaneous emphysema and impaired respiratory condition directly after the procedure. The patient recovered uneventfully with no evidence of postoperative infection. ${ }^{19}$

Collure et al. ${ }^{20}$ observed one case of multiple organ failure, of a group of four patients, after a laparoscopic operation. A patient with multimorbidities received a laparoscopic cholecystectomy to reduce the surgical trauma and the long recovery phase that follows an open procedure. The postoperative period for this patient was complicated by lobar pneumonia, which progressed into multiorgan failure and the patient died. ${ }^{20}$

Tobias et al. ${ }^{21}$ reported the first gynecological case in 1996. They did a safe diagnostic laparoscopy with a pneumoperitoneum pressure of $15 \mathrm{~mm} \mathrm{Hg}$ in a patient with a pelvic tumor. The operation was converted to laparotomy due to adhesions and the size of the tumor. $^{21}$

Baskin et al. ${ }^{24}$ described the first documented case of laparoscopically induced VP shunt failure in $1998 .{ }^{24}$ Postoperatively, the patient's condition was not improving, and he was experiencing intermittent apnea. He had to be re-intubated. An urgent head CT that the patient underwent shortly after experiencing the symptoms demonstrated a ventriculomegaly with no evidence of intracranial hemorrhage or pneumocephalus. The patient was indicated for another surgery. Intraoperatively, an isolated distal shunt obstruction was detected. A gentle irrigation cleared the occlusion. The authors believe that this shunt dysfunction occurred as a result of the peritoneal insufflation.

Allam et al. ${ }^{10}$ conducted a chart review of 23 patients from 1994 to 2003 in the USA and reported a 57\% rate of conversion to an open procedure, which was attributed to dense adhesion. Two patients required a shunt removal and replacement caused by a postoperative shunt infection. It has been documented that those two patients did not receive prophylactic antibiotics perioperatively. The rest of the patients was administered antibiotics pre-, intra, or postoperatively.

Raskin et al. ${ }^{36}$ demonstrated a case of a 24 -year-old female who had a VP shunt for more than 20 years, in 2011. She was diagnosed with endometriosis and underwent a laparoscopic bilateral salpingo-oophorectomy with the abdominal pressure of $50 \mathrm{~mm}$ $\mathrm{Hg}$. The procedure was converted to an open laparotomy due to significant abdominal adhesions.

Approximately 1 week after the surgery, the patient presented with increased agitation and abdominal distension. A CT of the pelvis revealed an abscess requiring a placement of a pelvic drain and a VP shunt externalization. A head CT prior to the shunt removal showed a pneumocephalus with air to be seen within the shunt valve. $^{36}$

\section{Monitoring of the ICP Intraoperatively/Protecting Techniques}

The first monitoring was reported by Collure et al. ${ }^{20}$ who documented the ongoing flow of the CSF in vivo in VP shunts with the pneumoperitoneum pressure of 10 to $15 \mathrm{~mm} \mathrm{Hg}^{20}$ 
Table 1: An overview of studies reported different laparoscopic operations (general surgery, gynecology, and urology) in patients with VP shunts

\begin{tabular}{|c|c|c|c|c|c|c|}
\hline Author, year & Cases sex (F/M) & Age (year) & Operations & Age of VP shunt & $\begin{array}{l}\text { Pneumoperitoneum } \\
\text { pressure }(\mathrm{mm} \mathrm{Hg})\end{array}$ & Complications \\
\hline Schwed, 1992 & $1(\mathrm{~F})$ & 73 & Cholecystectomy & 10 days & 15 & $\begin{array}{l}\text { Massive } \\
\text { subcutaneous } \\
\text { emphysema }\end{array}$ \\
\hline Collure, 1995 & $4(1 \mathrm{~F} / 3 \mathrm{M})$ & $39-75$ & Cholecystectomy & $1-20$ years & $10-15$ & $\begin{array}{l}\text { Multiple organ } \\
\text { failure ( } 1 \text { case), } \\
1 \text { conversion to } \\
\text { laparotomy }\end{array}$ \\
\hline Tobias, 1996 & $1(\mathrm{~F})$ & 64 & Staging laparoscopy & 7 years & 15 & $\begin{array}{l}\text { Conversion to } \\
\text { laparotomy }\end{array}$ \\
\hline Uzzo, 1997 & $2(1 \mathrm{~F} / 1 \mathrm{M})$ & $7 \& 8$ & $\begin{array}{l}\text { Bladder } \\
\text { autoaugmentation }\end{array}$ & 7 years & 12 & \\
\hline Gaskill, 1998 & $1(\mathrm{~F})$ & 16 & Fundoplication & 16 years & $\mathrm{N} / \mathrm{A}$ & \\
\hline Baskin, 1998 & $1(\mathrm{M})$ & 52 & Jejunostomy & 5 days & 15 & Shunt dysfunction \\
\hline Jackman, 2000 & $18(12 \mathrm{~F} / 6 \mathrm{M})$ & $13.2(1-28)$ & Colostomy & N.A & $16(12-20)$ & 3 shunt revisions \\
\hline Walker, 2000 & $10(\mathrm{~N} / \mathrm{A})$ & $1-16$ & $\begin{array}{l}\text { Funduplication, } \\
\text { cholecystectomy }\end{array}$ & $\mathrm{N} / \mathrm{A}$ & $10-15$ & \\
\hline Kimura, 2002 & $2(1 \mathrm{~F} / 1 \mathrm{M})$ & $9-13$ & Cholecystectomy & $\mathrm{N} / \mathrm{A}$ & $\mathrm{N} / \mathrm{A}$ & \\
\hline Brown, 2004 & $1(\mathrm{M})$ & 59 & $\begin{array}{l}\text { Prostatectomy in pros- } \\
\text { tate cancer }\end{array}$ & 28 years & 15 & \\
\hline Ravaoherisoa, 2004 & $1(\mathrm{~F})$ & 36 & $\begin{array}{l}\text { Resection of an ovarian } \\
\text { cyst }\end{array}$ & $\mathrm{N} / \mathrm{A}$ & $\mathrm{N} / \mathrm{A}$ & \\
\hline Al-Mufarrej, 2005 & $1(\mathrm{~F})$ & 34 & Cholecystectomy & 3 years & 13 & \\
\hline Martinez Ramos, 2006 & $1(\mathrm{~F})$ & 33 & Cholecystectomy & N/A & $\mathrm{N} / \mathrm{A}$ & \\
\hline Barina, 2007 & 3 & & Appendectomy & $\mathrm{N} / \mathrm{A}$ & $\mathrm{N} / \mathrm{A}$ & 2 shunt removal \\
\hline Li, 2008 & 7 & $47(2-79)$ & $\begin{array}{l}4 \text { cholecystectomy and } \\
3 \text { gastric bypass surgeries }\end{array}$ & $\mathrm{N} / \mathrm{A}$ & $\mathrm{N} / \mathrm{A}$ & \\
\hline Fraser, 2009 & 51 & 3.5 & $\begin{array}{l}\text { Fundoplication/ } \\
\text { gastrostomy }\end{array}$ & $1.3 \mathrm{yr}$ & & $\begin{array}{l}1 \text { shunt infection } \\
\text { and removal }\end{array}$ \\
\hline Hammill, 2010 & $1(\mathrm{~F})$ & 71 & Cholecystectomy & 10 years & $\mathrm{N} / \mathrm{A}$ & \\
\hline Allam, 2011 & 14 & 59 & Cholecystectomy & $\mathrm{N} / \mathrm{A}$ & $\mathrm{N} / \mathrm{A}$ & $\begin{array}{l}8 \text { conversions } \\
\text { to laparotomy, } \\
2 \text { cases of VP } \\
\text { shunt removal }\end{array}$ \\
\hline Bush, 2011 & $1(\mathrm{~F})$ & 34 & Robotic hysterectomy & 24 & 12 & \\
\hline Damrah, 2011 & $1(\mathrm{M})$ & 64 & Cholecystectomy & 6 & $12-15$ & \\
\hline Ghomi, 2011 & 1 & 21 & Hysteropexy & N/A & $5-15$ & \\
\hline Raskin, 2011 & $1(\mathrm{~F})$ & 24 & $\begin{array}{l}\text { Bilateral } \\
\text { salpingo-oophorectomy } \\
\text { in endometriosis }\end{array}$ & 20 years & 50 & $\begin{array}{l}\text { Pneumocephalus, } \\
\text { conversion to } \\
\text { laparotomy }\end{array}$ \\
\hline Sankpal, 2011 & $1(\mathrm{~F})$ & 32 & $\begin{array}{l}\text { Salpingotomy in ectopic } \\
\text { pregnancy }\end{array}$ & 10 years & 12 & \\
\hline Torigoe, $2013^{38}$ & $1(\mathrm{~F})$ & 51 & $\begin{array}{l}\text { Colectomy in cecal } \\
\text { cancer }\end{array}$ & $\mathrm{N} / \mathrm{A}$ & 8 & \\
\hline Cobianchi, 2014 & $1(\mathrm{M})$ & 41 & Cholecystectomy & 1 & 12 & \\
\hline Albarrak, 2015 & $1(\mathrm{~F})$ & 41 & Cholecystectomy & 3 years & 12 & \\
\hline Our case, 2020 & $1(\mathrm{~F})$ & 74 & $\begin{array}{l}\text { Biopsies in the cancer of } \\
\text { ovary }\end{array}$ & 12 & $14-20$ & \\
\hline
\end{tabular}

In 1997, Uzzo et al. ${ }^{22}$ used intraoperative ICP monitoring (introduction of the needle into the shunt reservoir) and saw a sudden increase in ICP by $12 \mathrm{~mm} \mathrm{Hg}$ to a maximum of $25 \mathrm{~mm} \mathrm{Hg}$. This was matched by an increase in the flow rate of the CSF from the shunt, and no adverse neurological effects were observed postoperatively.

Jackman et al. ${ }^{1}$ reviewed the intraoperatively documented records of 18 patients with a VP shunt after 19 consecutive laparoscopic operations, looking for signs of increased ICP. They reported no evidence of clinically increased ICP.

In 2004, Ravaoherisoa et al. ${ }^{28}$ reported a successful laparoscopic resection of an ovarian cyst and described the use of transcranial Doppler. There was no difference in cerebral blood flow when the patient was placed in the Trendelenburg position with an insufflation pressure of $10 \mathrm{~mm} \mathrm{Hg}$. However, there was a decrease 
in cerebral blood flow, when the abdominal pressure reached $15 \mathrm{~mm} \mathrm{Hg}$, and a rapid improvement was observed when the pressure decreased to $10 \mathrm{~mm} \mathrm{Hg}$.

Protecting the shunt from a potential reflux has always been a concern; therefore, several reports have been published addressing methods to temporarily protect the shunt during laparoscopic procedures.

There were several cases without any safety precautions being described, 1,8,17,20-26,32,34,37,39 but some surgeons used the following protecting techniques: clamping of the shunt intra-abdominally, ${ }^{19,29,38}$ clamping of the shunt through a skin incision, ${ }^{23}$ externalization of the shunt before insufflation ${ }^{10,27,30}$ or intraoperatively because of the possibility of a peritonitis, ${ }^{31}$ and packing of the shunt with a simple gauze, so that it is further away from the operative field. ${ }^{10,27}$ Two cases were reported with patients who were diagnosed with cancer, where clamping ${ }^{38}$ and intraoperative shunt externalization were the methods of choice. ${ }^{27}$

Some authors tried other methods to protect the shunts' function. In 2011, Ghomi et al. ${ }^{35}$ reported a case of laparoscopic hysteropexy, where the intraperitoneal pressure decreased from 15 to $5 \mathrm{~mm} \mathrm{Hg}$ every 30 minutes to minimize the changes in the ICP. This strategy was recommended as an option to prevent the possible shunt occlusions and a rise in the ICP.

\section{Discussion}

Laparoscopic surgery has become a preferred method of accessing and treating a variety of patients with intraperitoneal pathologies. Given the fact that laparoscopic interventions are now being used in a wider range of patients, surgeons can expect to encounter patients who have undergone placements of VP shunts and who present potential candidates for laparoscopic procedures.

The first VP shunt implantation was performed in 1908. ' Schwed et al. ${ }^{19}$ described the first laparoscopic operation in a patient with a VP shunt in 1992. The observation of a high ICP in animal models raised concerns about the safety of laparoscopy. ${ }^{41}$ In 1995, after monitoring the flow of CSF in VP shunts intraoperatively with a pneumoperitoneum pressure of 10 to $15 \mathrm{~mm} \mathrm{Hg}$, it was suggested that elective laparoscopic operations in patients with VP shunts can be done safely without the need of clamping or the necessity of any other manipulation with the shunt. ${ }^{20}$ Despite some successful reports, ${ }^{16,17}$ the first intraoperative ICP monitoring was executed in $1997 .{ }^{18}$ It showed a transient increase in the ICP during the laparoscopy and raised some questions whether a routine ICP monitoring should be advised.

To determine the potential for back-pressure failure and to observe the retrograde valve leaks, in 1999 Neale and Falk ${ }^{42}$ performed a very interesting experiment. An in vitro model was used to test nine forms of VP shunt valves and demonstrated that none of the valves showed any retrograde flow when exposed to pressure up to $350 \mathrm{~mm} \mathrm{Hg}$. The disruption in the seal on seven of nine shunts was, however, seen at pressure above $80 \mathrm{~mm} \mathrm{Hg}$. That presents a level of pressure that is approximately seven times above the maintained pressure during laparoscopic surgery. These findings were questioning the previous strategies of clamping or externalizing the end of the VP shunt to minimize the risk of a retrograde flow and were suggesting that these manipulations could possibly result in an increase in the ICP due to the blockage of normal CSF flow.

Five different valves simulating a closed system were studied by Matsumoto et al. ${ }^{43}$ in Japan in 2010 . There was no reflux of the $\mathrm{CO}_{2}$ for any of the valves with a pressure of less than $25 \mathrm{~mm} \mathrm{Hg}{ }^{8}$
The original shunting equipment was quite like a simple catheter. Soon after developing the shunt a no-reflow valve was added. This design was effective and did not change significantly thereafter. The risk of a sudden rise in the ICP was possibly overevaluated. ${ }^{39}$

The only case of pneumocephalus was reported by Raskin et al. ${ }^{36} \mathrm{He}$ reported that the pressure used during laparoscopy was $50 \mathrm{~mm} \mathrm{Hg}$ in a patient with a VP shunt that was placed more than 20 years prior to the procedure. The authors of this article were contacted, and it reveals that this pressure was documented from an operation report written by the gynecologist and could not be proved again.

The first reported complication was a respiratory failure caused by extensive subcutaneous emphysema after a laparoscopic surgery in a patient who had a VP shunt placed shortly before the procedure. ${ }^{15} \mathrm{~A}$ severe subcutaneous emphysema developed during the peritoneal insufflations of $\mathrm{CO}_{2}$ along a VP track created prior to 10 days. This case report implies that a newly placed VP catheter should be viewed as a relative contraindication to laparoscopy. This problem can be avoided by delaying the laparoscopy.

The first case of shunt failure ${ }^{20}$ was caused by a distal shunt obstruction due to an air lock or soft tissue impaction that was created during laparoscopic placement of a feeding jejunostomy tube. ${ }^{27}$ The patient required an urgent reoperation to clear the distal shunt. This could be avoided by checking the intraperitoneal end of the shunt, so that it does not get twisted or compressed.

There is only one case of robotic surgery (hysterectomy) and it was successful. ${ }^{33}$ It is an important case, because the Trendelenburg position in robotic surgery is steeper and there is no possibility of changing the degree of the Trendelenburg position after the docking. In this report, the authors temporarily clamped the shunt and the pressure throughout the operation was held at $12 \mathrm{~mm} \mathrm{Hg}{ }^{32}$

Long-lasting laparoscopic operations in VP shunt patients are still being discussed and operations that take longer than 3 hours are not recommended. ${ }^{39}$

An infection of a VP shunt is always an issue. Different studies proved that the shunt infection correlates with the number of exposures of the shunt system to a surgical glove. ${ }^{10}$ The specific advantages of laparoscopy in patients with a VP shunt may include less intra-abdominal adhesion formation and limited glove-toshunt contact. Theoretically these advantages of laparoscopy should decrease the need for shunt revision due to the loss of absorptive peritoneal surface and decrease in the risk of a shunt infection. ${ }^{1,12}$ Allam et al. ${ }^{10}$ have shown that intra-abdominal operations appear to result in a shunt infection with the rate of $9 \%$ within 30 days after the operation. The rate is like the reported findings about infections after a shunt insertion or a shunt revision. It is believed that a rational use of antibiotics can reduce the consequences of a CSF infection and decrease the likelihood of a subsequent infection. ${ }^{9,10}$ Burns and Dippe ${ }^{11}$ found that $53 \%$ of postoperative surgical site infections are not identified until after the patient was discharged from the hospital. Therefore, educating the patients and their families about the signs and symptoms of an altered VP shunt function (like headaches and photophobia) that may result from a postoperative infection is recommended. If the patients can recognize the symptoms of an infection after being discharging from the hospital, it could prevent potential serious complications. ${ }^{2,11,15}$ A preexisting VP shunt often causes clinically significant intra-abdominal adhesions, and these can lead to a higher conversion rate. ${ }^{10,21,36}$ 
In our case, we entered the peritoneum with the pressure of $20 \mathrm{~mm} \mathrm{Hg}$. Intraoperatively there were no complications and the patient had no complaints after the operation. Based on our case and the available data, we suggest that laparoscopic operations can be safely performed with only routine anesthetic monitoring in patients with a VP shunt. ${ }^{39} \mathrm{~A}$ careful placement of the trocar should be considered to avoid damaging the shunt and intraoperatively a careful manipulation with the peritoneal portion of the catheter is recommended as well. The literature did not show any benefit to using invasive ICP monitoring mainly because of the high possibility of risks like intracranial hemorrhage. Invasive perioperative ICP monitoring may be an option in very complex cases but generally a direct monitoring of the ICP during laparoscopic surgery does not appear to be necessary. The risk of retrograde failure of the valve system was shown to be minimal, even with an intra-abdominal pressure of $80 \mathrm{~mm} \mathrm{Hg}$. Currently there is no evidence that suggests clamping or externalization of the catheter is necessary. Manipulating with the VP shunt could potentially increase the ICP. The shunt material deteriorates with time, therefore the signs of increased ICP must be always considered. We believe that a consult with a neurosurgeon prior to the operation is advisable in order to verify the correct function of the shunt valve. The patient should be made aware of the potential risks associated with the procedure, including shunt obstruction, damage, and infection and should sign a patient's consent. ${ }^{27,39}$ The anesthesiologist should always inform the surgeon about the signs of increased ICP such as bradycardia and hypertension. ${ }^{33}$

A pelvic operation, lasting many hours, can affect the surgeons' ability to monitor the shunt, and this could potentially ${ }^{27}$ be the reason why any occlusions or back-pressure problems are overseen. In these cases, an intermittent release of the pneumoperitoneum, reduction of the Trendelenburg position, and inspection of the end of the shunt would give a possibility to avoid such complications.

Finally, an antegrade spread of malignant cells from the central nervous system through VP shunts was described, ${ }^{44-46}$ suggesting that if a retrograde valve failure occurred, the central nervous system could be inoculated with malignant cells from the pelvis. In our case, our patient showed no signs of metastasis after the follow-up of 8 months.

\section{Conclusion and Recommendations}

Laparoscopic surgery in adults with VP shunts utilizing routine anesthetic monitoring appears to be safe. However, it must be carried out in a facility that has optimal possibilities of monitoring the patient. The medications used by the anesthesiologist, pneumoperitoneum, and patient positioning can potentially elevate ICP. The safest way to avoid such complications is to be aware of their existence and to take precautionary measures to minimize their effects. ${ }^{39}$ Here are some recommendations from our experience and the reviewed articles:

- A neurosurgical consultation before and after the laparoscopic procedure to verify the proper functioning of the shunt and the valve is necessary. ${ }^{17}$

- The patient should be made aware of the potential risks associated with the procedure, including a shunt obstruction, damage, or infection. ${ }^{27}$

- The only relative contraindication should be if the catheter was recently placed, the risk of developing subcutaneous emphysema is high and to avoid this problem the laparoscopy should be delayed. ${ }^{39}$ If the tissue after placing the shunt becomes more fibrotic, then it is necessary to avoid the development of the emphysema. How much time exactly is needed for the tissue to become fibrotic is not known yet.

- It is recommended that the procedure is performed by an experienced laparoscopic surgeon in order to minimize the chance of spillage and contamination. ${ }^{17}$

- The surgeon should be aware of the location of the catheter within the abdominal wall to avoid inadvertent damage to the catheter during the placement of the trocar.

- It is important to ensure that the intraperitoneal portion of the catheter is not twisted or obstructed prior to decompression of the abdomen.

- Longer laparoscopic or robotic surgeries using a steep Trendelenburg position should be carried out with caution.

- An extended course of prophylactic antibiotics is recommended.

- Perioperative invasive ICP monitoring may be an option in very complex cases, but it is associated with some complications.

- To identify an infection in its early stages, a prompt treatment may prevent potential serious complications. ${ }^{2}$ Educating the patients and their families about the signs and symptoms of an altered VP shunt function (headaches and photophobia) that may result from a postoperative infection is useful. ${ }^{2}$

\section{Compliance with Ethical Standards}

No animal research has been used.

\section{Ethical Approval}

All procedures performed in studies involving human participants were in accordance with the ethical standards of the institutional and/or national research committee and with the 1964 Helsinki declaration and its later amendments or comparable ethical standards. This article does not contain any studies with human participants or animals performed by any of the authors.

\section{References}

1. Jackman SV, Weingart JD, Kinsman SL, et al. Laparoscopic surgery in patients with ventriculoperitoneal shunts: safety and monitoring. J Urol 2000;164(4):1352-1354. DOI: 10.1016/S0022-5347(05)67196-0.

2. Barina AR, Virgo KS, Mushi E, et al. Appendectomy for appendicitis in patients with a prior ventriculoperitoneal shunt. J Surg Res 2007;141(1):40-44. DOI: 10.1016/j.jss.2007.02.039.

3. Woodworth GF, McGirt MJ, Williams MA, et al. Cerebrospinal fluid drainage and dynamics in the diagnosis of normal pressure hydrocephalus. Neurosurgery 2009;64(5):919-925. DOI: 10.1227/01. NEU.0000341902.44760.10; discussion 25-6.

4. Vinchon $M$, Rekate $H$, Kulkarni AV. Pediatric hydrocephalus outcomes: a review. Fluids Barriers CNS 2012;9(1):18. DOI: 10.1186/2045-8118-918.

5. Rosenthal RJ, Hiatt JR, Phillips EH, et al. Intracranial pressure. Effects of pneumoperitoneum in a large-animal model. Surg Endosc 1997;11(4):376-380. DOI: 10.1007/s004649900367.

6. Czosnyka M, Pickard JD. Monitoring and interpretation of intracranial pressure. J Neurol Neurosurg Psychiatry 2004;75(6):813-821. DOI: 10.1136/jnnp.2003.033126.

7. Cooke SJ, Paterson-Brown S. Association between laparoscopic abdominal surgery and postoperative symptoms of raised intracranial pressure. Surg Endosc 2001;15(7):723-725. DOI: 10.1007/ s00464-001-0004-8.

8. Fraser JD, Aguayo P, Sharp SW, et al. The safety of laparoscopy in pediatric patients with ventriculoperitoneal shunts. J Laparoendosc Adv Surg Tech A 2009;19(5):675-678. DOI: 10.1089/lap.2009.0116. 
9. Kamine TH, Elmadhun NY, Kasper EM, et al. Abdominal insufflation for laparoscopy increases intracranial and intrathoracic pressure in human subjects. Surg Endosc 2016;30(9):4029-4032. DOI: 10.1007/ s00464-015-4715-7.

10. Allam E, Patel A, Lewis $G$, et al. Cholecystectomy in patients with prior ventriculoperitoneal shunts. Am J Surg 2011;201(4):503-507. DOI: 10.1016/j.amjsurg.2010.05.006.

11. Burns SJ, Dippe SE. Postoperative wound infections detected during hospitalization and after discharge in a community hospital. Am J Infect Control 1982;10(2):60-65. DOI: 10.1016/0196-6553(82)90004-9.

12. Moore RG, Kavoussi LR, Bloom DA, et al. Postoperative adhesion formation after urological laparoscopy in the pediatric population. J Urol 1995;153(3 Pt 1):792-795.

13. Vinchon $M$, Dhellemmes P. Cerebrospinal fluid shunt infection: risk factors and long-term follow-up. Childs Nerv Syst 2006;22(7):692-697. DOI: 10.1007/s00381-005-0037-8.

14. Kulkarni AV, Drake JM, Lamberti-Pasculli M. Cerebrospinal fluid shunt infection: a prospective study of risk factors. J Neurosurg 2001;94(2):195-201. DOI: 10.3171/jns.2001.94.2.0195.

15. Sarguna P, Lakshmi V. Ventriculoperitoneal shunt infections. Indian J Med Microbiol 2006;24(1):52-54. DOI: 10.4103/0255-0857.19896.

16. Iglesias S, Ros B, Martín Á, et al. Factors related to shunt survival in paediatric hydrocephalus. Could failure be avoided? Neurocirugia (Astur) 2017;28(4):159-166. DOI: 10.1016/j.neucir.2016.12.004.

17. Albarrak AA, Khairy S, Ahmed AM. Laparoscopic cholecystectomy for acute calcular cholecystitis in a patient with ventriculoperitoneal shunt: a case report and literature review. Case Rep Surg 2015;2015:845613. DOI: 10.1155/2015/845613.

18. Liberati A, Altman DG, Tetzlaff J, et al. The PRISMA statement for reporting systematic reviews and meta-analyses of studies that evaluate healthcare interventions: explanation and elaboration. BMJ 2009;339(jul21 1):b2700. DOI: 10.1136/bmj.b2700.

19. Schwed DA, Edoga JK, McDonnell TE. Ventilatory impairment during laparoscopic cholecystectomy in a patient with a ventriculoperitoneal shunt. J Laparoendosc Surg 1992;2(1):57-59. DOI: 10.1089/ Ips.1992.2.57.

20. Collure DW, Bumpers HL, Luchette FA, et al. Laparoscopic cholecystectomy in patients with ventriculoperitoneal (VP) shunts. Surg Endosc 1995;9(4):409-410. DOI: 10.1007/BF00187161.

21. Tobias DH, Smith HO, Runowicz CD, et al. Laparoscopic surgery in patients with a ventriculoperitoneal shunt. A case report. J Reprod Med 1996;41(2):129-131.

22. Uzzo RG, Bilsky M, Mininberg DT, et al. Laparoscopic surgery in children with ventriculoperitoneal shunts: effect of pneumoperitoneum on intracranial pressure-preliminary experience. Urology 1997;49(5):753-757. DOI: 10.1016/S0090-4295(97)00233-1.

23. Gaskill SJ, Cossman RM, Hickman MS, et al. Laparoscopic surgery in a patient with a ventriculoperitoneal shunt: a new technique. Pediatr Neurosurg 1998;28(2):106-107. DOI: 10.1159/000028631.

24. Baskin JJ, Vishteh AG, Wesche DE, et al. Ventriculoperitoneal shunt failure as a complication of laparoscopic surgery. JSLS 1998;2(2):177180.

25. Walker DH, Langer JC. Laparoscopic surgery in children with ventriculoperitoneal shunts. J Pediatr Surg 2000;35(7):1104-1105. DOI: 10.1053/jpsu.2000.7835.

26. Kimura T, Nakajima K, Wasa M, et al. Successful laparoscopic fundoplication in children with ventriculoperitoneal shunts. Surg Endosc 2002;16(1):215. DOI: 10.1007/s00464-001-4104-2.

27. Brown JA, Medlock MD, Dahl DM. Ventriculoperitoneal shunt externalization during laparoscopic prostatectomy. Urology 2004;63(6):1183-1185. DOI: 10.1016/j.urology.2004.02.028.

28. Ravaoherisoa J, Meyer P, Afriat R, et al. Laparoscopic surgery in a patient with ventriculoperitoneal shunt: monitoring of shunt function with transcranial Doppler. Br J Anaesth 2004;92(3):434-437. DOI: 10.1093/bja/aeh067.

29. Al-Mufarrej F, Nolan C, Sookhai S, et al. Laparoscopic procedures in adults with ventriculoperitoneal shunts. Surg Laparosc Endosc Percutan Tech 2005;15(1):28-29. DOI: 10.1097/01. sle.0000153733.78227.8f.

30. Martinez Ramos D, Gibert Gerez J, Salvador Sanchis JL. Laparoscopic surgery in patients with a ventriculoperitoneal shunt. Rev Esp Enferm Dig 2006;98(10):795-796. DOI: 10.4321/s1130-01082006001000015.

31. Li G, Dutta S. Perioperative management of ventriculoperitoneal shunts during abdominal surgery. Surg Neurol 2008;70(5):492-495. DOI: 10.1016/j.surneu.2007.08.050; discussion 5-7.

32. Hammill CW, Au T, Wong LL. Laparoscopic cholecystectomy in a patient with a ventriculoperitoneal shunt. Hawaii Med J 2010;69(4):103-104.

33. Bush SH, Greg Heywood S, Calhoun BC. Robotic-assisted hysterectomy in a patient with a ventriculoperitoneal shunt. J Robot Surg 2011;5(4):291-293. DOI: 10.1007/s11701-011-0264-9.

34. Damrah O, Naik P, Fusai G, et al. Is laparoscopic cholecystectomy safe for acute cholecystitis in the presence of ventriculo-peritoneal shunt? Int J Surg Case Rep 2011;2(6):157-158. DOI: 10.1016/j.ijscr.2011.04.003.

35. Ghomi A, Askari R, Kasturi S, et al. Laparoscopic hysteropexy in a patient with spina bifida and ventriculoperitoneal shunt. JSLS 2011;15(2):254-256. DOI: 10.4293/108680811X13071180407159.

36. Raskin J, Guillaume DJ, Ragel BT. Laparoscopic-induced pneumocephalus in a patient with a ventriculoperitoneal shunt. Pediatr Neurosurg 2011;46(5):390-391. DOI: 10.1159/000322898.

37. Sankpal R, Chandavarkar A, Chandavarkar M. Safety of laparoscopy in Ventriculoperitoneal shunt patients. J Gynecol Endosc Surg 2011;2(2):91-93. DOI: 10.4103/0974-1216.114082.

38. Torigoe T, Koui S, Uehara T, et al. Laparoscopic cecal cancer resection in a patient with a ventriculoperitoneal shunt: a case report. Int J Surg Case Rep 2013;4(3):330-333. DOI: 10.1016/j.ijscr.2013.01.005.

39. Cobianchi L, Dominioni T, Filisetti C, et al. Ventriculoperitoneal shunt and the need to remove a gallbladder: time to definitely overcome the feeling that laparoscopic surgery is contraindicated. Ann Med Surg (Lond) 2014;3(3):65-67. DOI: 10.1016/j.amsu.2014.03.005.

40. Torigoe M, Maeshima K, Takeshita Y. Congenital intrahepatic portosystemic venous shunt presenting with paraparesis as the initial symptom. Intern Med 2013;52(21):2439-2442. DOI: 10.2169/ internalmedicine.52.0881.

41. Josephs LG, Este-McDonald JR, Birkett DH, et al. Diagnostic laparoscopy increases intracranial pressure. J Trauma 1994;36(6):815818. DOI: 10.1097/00005373-199406000-00011; discussion 8-9.

42. Neale ML, Falk GL. In vitro assessment of back pressure on ventriculoperitoneal shunt valves. is laparoscopy safe? Surg Endosc 1999;13(5):512-515. DOI: 10.1007/s004649901024.

43. Matsumoto $T$, Endo $\mathrm{Y}$, Uchida $\mathrm{H}$, et al. An examination of safety on laparoscopic surgery in patients with ventriculoperitoneal shunt by a $\mathrm{CO}_{2}$ reflux experiment. J Laparoendosc Adv Surg Tech A 2010;20(3):231-234. DOI: 10.1089/lap.2010.0038.

44. Gattuso P, Carson HJ, Attal H, et al. Peritoneal implantation of meningeal melanosis via ventriculoperitoneal shunt: a case report and review of the literature. Diagn Cytopathol 1995;13(3):257-259. DOI: 10.1002/dc.2840130314.

45. Wong KT, Koh KB, Lee $\mathrm{SH}$, et al. Intracranial germinoma metastasizing via a ventriculo-peritoneal shunt. Singapore Med J 1996;37(4):441442.

46. Ng JJ, Teo KA, Shabbir A, et al. Widespread intra-abdominal carcinomatosis from a rhabdoid meningioma after placement of a ventriculoperitoneal shunt: a case report and review of the literature. Asian J Neurosurg 2018;13(2):386-393. DOI: 10.4103/ajns. AJNS 42 15. 